\title{
Knowledge and Awareness of Saudi Public Regarding the Outbreak and Prevention of COVID-19 in Saudi Arabia; a Questionnaire-Based Study
}

\author{
Reem Al Madani ${ }^{1} \&$ Shahzeb H. Ansari ${ }^{1}$ \\ ${ }^{1}$ Riyadh Elm University, Riyadh, Kingdom of Saudi Arabia \\ Correspondence: Reem Al Madani, Riyadh Elm University, Riyadh, Kingdom of Saudi Arabia. E-mail: \\ Reem.m.almadani@gmail.com
}

Received: August 27, 2020 Accepted: October 21, 2020 Online Published: November 2, 2020

doi:10.5539/gjhs.v12n13p67 URL: https://doi.org/10.5539/gjhs.v12n13p67

\begin{abstract}
Introduction: The dispersion of severe COVID-19 has already occupied on pandemic extents, disturbing over 100 nations in a matter of months. A worldwide response to formulate health systems global is imperious.

Materials and Methods: This is a cross sectional study conducted among the Saudi general public using an online survey. Saudis (male and female) of all ages willing to participate in this study were requested to fill up the survey. An online questionnaire was designed using Google Forms with questions related to personal and demographic information followed by COVID-10 related questions.
\end{abstract}

Results: A total of $\mathrm{N}=1026$ subjects participated in this study and responded by completing the online survey. They were divided into groups including gender, age, education and profession type. As far as gender was concerned, 243 (23.7\%) males and 783 (76.3\%) females took part.

Conclusion: Overall knowledge of Saudis regarding COVID-19 is above average.

Keywords: COVID-19, Saudi public, knowledge

\section{Introduction.}

A new coronavirus has led to a current outburst of viral pneumonia in China. People to people spread has been proved, but, to our facts, spread of the novel coronavirus that causes coronavirus disease 2019 (COVID-19) from an asymptomatic carrier with usual chest computed tomography (CT) results has not been stated (Bai et al., 2020).

The dispersion of severe COVID-19 has already occupied on pandemic extents, disturbing over 100 nations in a matter of months. A worldwide response to formulate health systems global is imperious. Though restraint procedures in China have reduced new cases by more than $90 \%$, this drop is not the case elsewhere, and Italy has been mainly affected. There is now severe apprehension regarding the Italian national health system's volume to efficiently respond to the needs of patients who are sick and need rigorous care for COVID-19. The proportion of patients in intensive care stated every day in Italy between March 1 and March 11, 2020, has constantly been between $9 \%$ and $11 \%$ of patients who are vigorously sick (Remuzzi \& Remuzzi, 2020).

The current COVID-19 pandemic is a Public Health Emergency of International Concern (PHEIC), and the rise of new origins of spread, such as South Korea and Iran, besides Wuhan, China, should attract attention to possible worldwide spread. Of worry is the unceasing Umrah visit to Saudi Arabia by Muslim pilgrims from more than 180 nations. Moreover, the non-pilgrim air traffic (39 million people in 2018), Saudi Arabia received $7 \cdot 5$ million Umrah visa holders in 2019. Umrah visitors to Saudi Arabia do not usually get organized health safety communications in their home countries. Hand washing and respiratory sanitation are part of the rites and obligatory five times a day, yet the overcapacity and other risk factors may compensate the assistances. Limitations on executing Umrah is an extremely delicate geopolitical proposal that needs further inspection, particularly when numerous countries are affected (Ebrahim \& Memish, 2020).

A study was conducted in China to assess the knowledge of general public regarding this issue. A huge majority of the partakers apprehended a hopeful attitude towards the COVID-19 epidemic: $90.8 \%$ thought that COVID-19 will be effectively controlled, and $97.1 \%$ had assurance that China can win the encounter against the virus. In 
spite of this, the practices of Chinese inhabitants were very vigilant: almost all evaded packed places (96.4\%) and wore masks when exiting their home (98.0\%) throughout the speedy growth period of the COVID-19 outbreak. They also examined the features of KAP towards COVID-19 and acknowledged some demographic factors related with KAP; these results are useful for public health policy-makers and health workers to identify target people for COVID-19 prevention and health education (Zhong et al., 2020).

Aim of the study: To determine the level of knowledge regarding COVID-19 among the Saudis and compare their knowledge on the basis of gender, age and educational levels.

\section{Materials and Methods}

\subsection{Study Design}

This is a cross sectional study conducted among the Saudi general public using an online survey.

\subsection{Study Sample}

Saudis (male and female) of all ages willing to participate in this study were requested to fill up the survey. A total of 1000 subjects were targeted using social media.

\subsection{Study Instrument}

An online questionnaire was designed using Google Forms with questions related to personal and demographic information followed by COVID-10 related questions.

\subsection{Instrument Validity and Reliability}

A pilot study was conducted by letting the survey filled by 20 participants and the data was inserted in SPSS version 22 to determine the reliability by using Chronbach's coefficient alpha (Value was .844). Validity of the questionnaire was tested by sending it to experience researchers in REU and no changes were made.

\subsection{Statistical Analysis}

Collected data was analyzed using SPSS version 22, where descriptive as well as inferential statistics was conducted. Comparisons between groups were made with the value of significance kept under 0.05 . Chi-square test was done to achieve this purpose.

\section{Results}

A total of $\mathrm{N}=1026$ subjects participated in this study and responded by completing the online survey. They were divided into groups including gender, age, education and profession type. As far as gender was concerned, 243 (23.7\%) males and 783 (76.3\%) females took part (Figure 1). When grouped on the basis of age, $25(2.4 \%)$ were less than 18 years, $599(58.4 \%)$ were $18-30$ years, $262(25.5 \%)$ were $31-40$ years, $114(11.1 \%)$ were $41-50$ years, $21(2 \%)$ were 51-60 years and $5(0.5 \%)$ were more than 60 years (Figure 2). Regarding the educational levels, 12 $(1.2 \%)$ had education less than high school, $193(18.8 \%)$ had high school education and $821(80 \%)$ had university education (Figure 3). 304 (29.6\%) worked in a profession related to health, whereas rest of them didn't (Figure 4).



Figure 1. Gender ratio of the study participants 




Figure 2. Age groups of the study participants

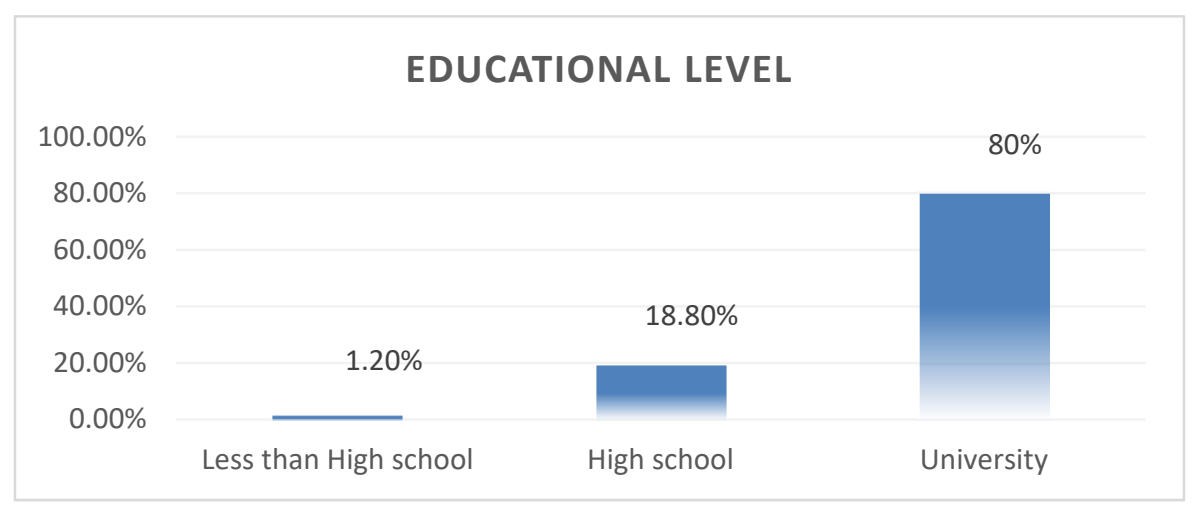

Figure 3. Educational levels of the study participants



Figure 4. Profession type of study participants 
Table 1. Survey questions and their response frequencies in percentage

\begin{tabular}{|c|c|}
\hline Survey Questions & Frequencies $(\%)$ \\
\hline \multirow{3}{*}{ Covid-19 was developed intentionally as a bioweapon. } & Yes: $34.6 \%$ \\
\hline & No: $20.6 \%$ \\
\hline & Not sure: $44.8 \%$ \\
\hline \multirow{4}{*}{ How many people in KSA have been infected until April $2020 ?$} & $<10000: 14.9 \%$ \\
\hline & 10000-20000: $14.9 \%$ \\
\hline & 20000-30000: $24 \%$ \\
\hline & $>30000: 46.2 \%$ \\
\hline \multirow{4}{*}{ Percentage of people died from COVID-19 in KSA. } & $<5 \%: 67.5 \%$ \\
\hline & $5-10 \%: 24 \%$ \\
\hline & $10-20 \%: 6.6 \%$ \\
\hline & $>20 \%: 1.9 \%$ \\
\hline \multirow{3}{*}{ Age group most likely to die from COVID-19. } & Children: $1.5 \%$ \\
\hline & Adults: $8.2 \%$ \\
\hline & Older adults: $90.4 \%$ \\
\hline \multirow{3}{*}{$\begin{array}{l}\text { People with other diseases who contract COVID-19 are more likely to } \\
\text { die. }\end{array}$} & Yes: $76 \%$ \\
\hline & No: $6 \%$ \\
\hline & Not sure: $18 \%$ \\
\hline \multirow{6}{*}{ What are the signs and symptoms of COVID-19? } & Cough only: $0.2 \%$ \\
\hline & Shortness of breath only: $0.8 \%$ \\
\hline & Cough and shortness of breath: $1 \%$ \\
\hline & Fever and cough only: $3.7 \%$ \\
\hline & Fever, cough and shortness of breath: $57.4 \%$ \\
\hline & Some people have no symptoms: $36.9 \%$ \\
\hline \multirow{4}{*}{ If symptoms appear, what would you do? } & Wait until symptoms get severe: $12.5 \%$ \\
\hline & Visit hospital emergency immediately: $5.2 \%$ \\
\hline & Visit nearby clinic and consult physician: $1.4 \%$ \\
\hline & Call 937 and seek instructions: $81 \%$ \\
\hline \multirow{4}{*}{ Actions helping preventing spread of COVID-19. } & Washing hands: $1.7 \%$ \\
\hline & Avoid close contact with people: $2.5 \%$ \\
\hline & $\begin{array}{l}\text { Avoid touching your eyes, mouth and face: } \\
0.8 \%\end{array}$ \\
\hline & All of the above: $95 \%$ \\
\hline \multirow{3}{*}{ Wearing mask can prevent spread of COVID-19. } & Yes: $49 \%$ \\
\hline & No: $28.5 \%$ \\
\hline & Not sure: $22.5 \%$ \\
\hline \multirow{3}{*}{ Major cause of spread. } & Droplets of infected people: $3.2 \%$ \\
\hline & Shaking hands with infected people: $3.4 \%$ \\
\hline & Both of the above: $93.4 \%$ \\
\hline \multirow{3}{*}{ Suspending air/ground travel can reduce the spread. } & Yes: $81.7 \%$ \\
\hline & No: $6.1 \%$ \\
\hline & Not sure: $12.2 \%$ \\
\hline \multirow{3}{*}{ Receiving package through courier can increase the risk of spread. } & Yes: $19.8 \%$ \\
\hline & No: $25.6 \%$ \\
\hline & Not sure: $54.6 \%$ \\
\hline
\end{tabular}


Table 2. Correlation of age and survey responses

\begin{tabular}{lcc}
\hline Survey Questions & Pearson Correlation Value & P-value \\
\hline Covid-19 was developed intentionally as a bioweapon. & .093 & $.003 *$ \\
How many people in KSA have been infected until April 2020? & -.047 & .130 \\
Percentage of people died from COVID-19 in KSA. & .012 & .692 \\
Age group most likely to die from COVID-19. & .038 & .228 \\
People with other diseases who contract COVID-19 are more likely to die. & .044 & .157 \\
What are the signs and symptoms of COVID-19? & -.001 & .974 \\
If symptoms appear, what would you do? & .004 & .891 \\
Actions helping preventing spread of COVID-19. & -.031 & .325 \\
Wearing mask can prevent spread of COVID-19. & .040 & .196 \\
Major cause of spread. & .049 & .117 \\
Suspending air/ground travel can reduce the spread. & .033 \\
Receiving package through courier can increase the risk of spread. & .021 & .291 \\
\hline
\end{tabular}

Table 3. Correlation of education and survey responses

\begin{tabular}{llc}
\hline Survey Questions & Pearson Correlation Value & P-value \\
\hline Covid-19 was developed intentionally as a bioweapon. & .001 & .987 \\
How many people in KSA have been infected until April 2020? & .051 & .101 \\
Percentage of people died from COVID-19 in KSA. & -.103 & $.001^{*}$ \\
Age group most likely to die from COVID-19. & .018 & .564 \\
People with other diseases who contract COVID-19 are more likely to die. & -.074 & $.018^{*}$ \\
What are the signs and symptoms of COVID-19? & -.039 & .208 \\
If symptoms appear, what would you do? & .048 & .127 \\
Actions helping preventing spread of COVID-19. & .061 & .051 \\
Wearing mask can prevent spread of COVID-19. & .043 & .168 \\
Major cause of spread. & -.019 & .539 \\
Suspending air/ground travel can reduce the spread. & .011 & .735 \\
Receiving package through courier can increase the risk of spread. & .010 & .751 \\
\hline
\end{tabular}

\section{Discussion}

This study was conducted keeping in mind the current pandemic that has turned the whole world upside down. COVID-19 has taken hundreds of thousands lives and it has proven to be one of the deadliest pandemics in the recent times. We aimed to measure the level of awareness and knowledge of Saudis towards the protection from COVID-19 as well as the symptoms associated with it. Results suggest that the over all knowledge of study participants was above average. This included the knowledge of symptoms, measures towards prevention and management options. A similar study conducted in India among general public revealed a moderate level of knowledge regarding the COVID-19 infection as well as preventive measures associated with it (Roy et al., 2020).

Another investigation took place in USA among the general public to assess their knowledge regarding the spread and prevention of COVID-19. Their results suggested an above average knowledge among the study participants (Geldsetzer, 2020). These findings are similar to those of our study.

An Egyptian study also determined the level of knowledge among their citizens which revealed a very high percentage of awareness. Most of the answers to related questions had the correct response of more than $90 \%$ (Abdelhafiz et al., 2020). These findings were much better than the ones we found among our study participants. 
However, a Kenyan based study showed a relatively lower level of knowledge among the general public when inquired about the preventive measures regarding COVID-19 (Austrian et al., 2020).

\section{Conclusion}

Upon the results found in the current study, we conclude that overall knowledge of Saudis regarding COVID-19 is above average, age had no significant association on the knowledge levels, and education as well did not have any bearing on the knowledge levels.

\section{Competing Interests Statement}

The authors declare that there are no competing or potential conflicts of interest.

\section{References}

Bai, Y., Yao, L., Wei, T., Tian, F., Jin, D.Y., Chen, L., \& Wang, M. (2020). Presumed asymptomatic carrier transmission of COVID-19. Jama, 323(14), 1406-1407. https://doi.org/10.1001/jama.2020.2565

Remuzzi, A., \& Remuzzi, G. (2020). COVID-19 and Italy: what next?. The Lancet. https://doi.org/10.1016/S0140-6736(20)30627-9

Ebrahim, S. H., \& Memish, Z. A. (2020). COVID-19: preparing for superspreader potential among Umrah pilgrims to Saudi Arabia. Lancet (London, England), 395(10227), p.e48. https://doi.org/10.1016/S0140-6736(20)30466-9

Zhong, B. L., Luo, W., Li, H. M., Zhang, Q. Q., Liu, X. G., Li, W. T., \& Li, Y. (2020). Knowledge, attitudes, and practices towards COVID-19 among Chinese residents during the rapid rise period of the COVID-19 outbreak: a quick online cross-sectional survey. International journal of biological sciences, 16(10), 1745. https://doi.org/10.7150/ijbs.45221

Roy, D., Tripathy, S., Kar, S. K., Sharma, N., Verma, S. K., \& Kaushal, V. (2020). Study of knowledge, attitude, anxiety \& perceived mental healthcare need in Indian population during COVID-19 pandemic. Asian Journal of Psychiatry, 102083. https://doi.org/10.1016/j.ajp.2020.102083

Geldsetzer, P. (2020). Knowledge and perceptions of COVID-19 among the general public in the United States and the United Kingdom: A cross-sectional online survey. Annals of internal medicine. https://doi.org/10.7326/M20-0912

Abdelhafiz, A. S., Mohammed, Z., Ibrahim, M. E., Ziady, H. H., Alorabi, M., Ayyad, M., \& Sultan, E. A. (2020). Knowledge, perceptions, and attitude of egyptians towards the novel coronavirus disease (COVID-19). Journal of Community Health, 1-10. https://doi.org/10.1007/s10900-020-00827-7

Austrian, K., Pinchoff, J., Tidwell, J. B., White, C., Abuya, T., Kangwana, B., ... \& Mwanga, D. (2020). COVID-19 related knowledge, attitudes, practices and needs of households in informal settlements in Nairobi, Kenya. Social ence Electronic Publishing. https://doi.org/10.2139/ssrn.3576785

\section{Copyrights}

Copyright for this article is retained by the author(s), with first publication rights granted to the journal.

This is an open-access article distributed under the terms and conditions of the Creative Commons Attribution license (http://creativecommons.org/licenses/by/4.0/). 